\title{
As noções de letramento e autoria em suas relações com a dispersão e a deriva de sentidos
}

\author{
Debbie Mello Noble (D) \\ Universidade do Sul de Santa Catarina (UNISUL)
}

○ OPEN ACCESS

EDITADO POR Raquel Freitag

AVALIADO POR Nádson Araújo

SOBRE OS AUTORES

Debbie Mello Noble Contribuiu com Maria Helena

Favaro. Papéis: escrita rascunho original, análise e edição.

Maria Helena Favaro Contribuiu com Debbie Mello

Noble. Papéis: escrita rascunho original, análise e edição.

DATAS

Recebido: 12/06/2020

Aceito: $28 / 06 / 2020$

Publicado: 09/07/2020

COMO CITAR

Noble, D. M.; Favaro, M. H.

(2020)

As noções de letramento e autoria em suas relações com a dispersão e a deriva de sentidos. Revista da Abralin, v. 19, n. 02, p.
Maria Helena Favaro (D)

Universidade do Sul de Santa Catarina (UNISUL)

\section{RESUMO}

A fala da professora Leda Tfouni, intitulada Letramento e Autoria: Dispersão e Deriva de Sentidos, ocorreu em 05 de junho de 2020 durante a série de conferências e mesas-redondas promovidas pela Abralin. O objetivo da conferência proferida por Tfouni foi amalgamar reflexões acerca da forma como vem desenvolvendo as noções de letramento e autoria, especialmente em suas relações com os discursos orais e escritos. Tfouni entende que a autoria se dá mesmo em discursos orais, onde é mais interessante observá-la, uma vez que a deriva de sentidos é menos controlada e onde se instaura a dispersão inerente ao sujeito e a equivocidade como real da língua.

\section{ABSTRACT}

Professor's Leda Tfouni speech, entitled Literacy and Authorship: Dispersion and Drift of Senses, took place on June 5th, 2020, during the series of conferences and roundtables promoted by Abralin. The purpose of the conference given by Tfouni was to amalgamate reflexions on how she has been developing the notions of literacy and authorship, especially in their relations with oral and written discourses. Tfouni understands that authorship even happens in oral discourses, where it is more interestingly observed, since the drift of senses is less controlled and where the dispersion inherent to the subject and the equivocity as the real of the language is established. 


\section{REVISTA DA ABRALIN}

PALAVRAS-CHAVE

Letramento. Autoria. Deriva de Sentidos.

\section{KEYWORDS}

Literacy. Authorship. Drift of Senses.

A fala da professora Leda Tfouni, intitulada Letramento e Autoria: Dispersão e Deriva de Sentidos, ocorreu em 05 de junho de 2020, durante a série de conferências e mesas-redondas promovidas pela Abralin de forma on-line. A autora iniciou sua fala destacando a importância do evento on-line, a fim de marcar a presença da área de linguística e da ciência brasileira. O objetivo da conferência proferida por Tfouni foi amalgamar reflexões acerca da temática do letramento e autoria.

Primeiramente, faz-se necessário destacar o percurso teórico da autora em sua trajetória profissional, o qual se deu em torno do conceito de letramento, distinguindo-o do conceito de alfabetização, e considerado em sua dimensão sócio-histórica "como um processo que precisa ser remetido às transformações da sociedade quando suas atividades passam a ser permeadas por um sistema de escrita com uso generalizado" (TFOUNI, 2020). Para compreender melhor este conceito, é necessário observar que, em uma sociedade letrada, as práticas são inevitavelmente baseadas em letramento, sendo a escrita mediadora dessas práticas. Outro importante ponto destacado pela autora é a relação não linear entre ser letrado e ser alfabetizado: isso é bem ilustrado pela autora através de exemplos de textos bem escritos (do ponto de vista da coerência e da autoria, como veremos mais à frente) produzidos por pessoas recém-alfabetizadas em comparação a textos sem qualquer traço de coesão e coerência produzidos por pessoas com formação universitária.

Tfouni ressalta que existe um conhecimento sobre a escrita que o sujeito adquire antes mesmo de aprender a ler e a escrever. Dessa forma, não há sujeitos não letrados, pois a sua inserção direta ou indireta nessas práticas é inevitável. A autora propõe, dessa forma, que há letramentos variados, inclusive sem alfabetização. Por essa razão, apesar das práticas letradas afetarem a todos os indivíduos, isso não ocorre de igual maneira. Nesse sentido, as diferenças entre os níveis de letramento são da ordem do discurso, e não da língua. Isso pode ser observado quando se lança um olhar para a sociedade percebendo a divisão de classes, na qual não é possível haver uma partilha de conhecimentos, sendo alguns grupos sociais, mesmo com certo grau de letramento, excluídos desse processo de produção, sendo, portanto, marginalizados.

A inserção teórica da autora na Análise do Discurso está diretamente associada a este olhar lançado por ela para os processos de letramento em sua relação com a autoria. Nessa teoria, não está em jogo a observação do indivíduo empírico, mas sim as posições de sujeito envolvidas no processo, as quais não são intercambiáveis nem equivalentes, devido aos processos de legitimação que atravessam as práticas letradas. Esses processos se relacionam com a existência dessas posições, 


\section{REVISTA DA ABRALIN}

determinando quem está autorizado ou não a ocupar certos lugares e que certas práticas letradas circulem de diferentes formas em determinados momentos sócio-históricos.

Nesse sentido, a dicotomia entre língua oral e escrita não se sustenta nas práticas de letramento. É isso que Gallo (1992) denomina de Discursos de Escrita e de Oralidade, não condicionando estes a estarem grafados ou não, uma vez que o que determina esses discursos são justamente as práticas de legitimação. Para Tfouni (2020), isso não impede que o sujeito ocupe uma posição de autoria ao inserirse nessas discursividades, mesmo possuindo um domínio mais precário da escrita como grafia.

Por esse motivo, Tfouni defende que a autoria é um critério adequado para falar sobre isso, uma vez que a autoria é uma posição discursiva, a partir da qual o sujeito consegue estruturar seu discurso de acordo com um princípio organizador que é, paradoxalmente, também um movimento de deriva e dispersão dos sentidos inerente a qualquer sujeito. Esse processo é paradoxal na medida em que o sujeito precisa controlar a dispersão para dar ao seu discurso um efeito de fecho, ou seja, uma aparente unidade. Nesse processo, há um descarte de outras formas possíveis de dizer, marcando a autoria pelo desejo de completude e pela perda.

Nessa perspectiva, Tfouni situa o trabalho de autoria no que é próprio da língua, o que Pêcheux traz como atravessado por:

uma divisão discursiva entre dois espaços: o da manipulação de significações estabilizadas, normatizadas por uma higiene pedagógica do pensamento, e o das transformações do sentido, escapando a qualquer norma estabelecida a priori. (PÊCHEUX, 1990, p. 51).

A deriva é, portanto, a irrupção do real: uma vez que o real está na falta, pelo processo de deriva, outras possibilidades de significação irrompem, quebrando a ilusão da unidade. Dessa forma, o autor é aquele que trai, em seu texto, a luta com as palavras, pois, em seu processo de contenção dos sentidos, se depara com um duplo real da língua: a sistematicidade e a equivocidade.

É na enunciação, portanto, que essas duas ordens heterogêneas agem, segundo Tfouni, em uma "dinâmica especial da enunciação": na fala, percebemos os falsos começos, as glosas, as tentativas de dizer de outra forma etc. Se dá a materialização de um embate entre, por um lado, a ilusão de livre escolha - apontada por Tfouni como a essência do trabalho de autoria -, e, por outro, a irrupção do real, fazendo furo no simbólico e quebrando a transparência imaginária da língua.

Esse embate entre consciente e inconsciente revela que o indivíduo não é senhor de suas escolhas, como sempre alertou a Análise do Discurso: nesses momentos, quando faltam as palavras, ou os significantes não se prendem bem uns aos outros, quando não se sabe bem como prosseguir, é que o sujeito emerge.

Nesse sentido, a ausência de autoria - ou seja, a impossibilidade de textualização - é um processo de deriva e de dispersão. Quando a autoria não se instala, ocorre a dispersão, que é também uma dimensão do sujeito. Os recursos que seguram essa posição e permitem que se produza texto são, segundo Tfouni (2020):

os shifters, formas lexicais da dêixis e da anáfora que, quando empregadas adequadamente, seguram o ato de referência, indicando, por substituição, a palavra certa, que foi omitida. Eles possibilitam um 


\section{REVISTA DA ABRALIN}

retorno ao já formulado, ao intradiscurso e realizam um movimento de contenção que produz um efeito de controle da dispersão, uma das características da autoria.

Diante disso, podemos afirmar que dispersão não se dá por uma incapacidade do sujeito da ordem da linguagem, mas, alerta Tfouni, se dá por um impedimento do enlace entre os significantes, talvez porque os sentidos que começam a ser mobilizados pelo sujeito sejam da ordem do insuportável. Diante do não sentido, o sujeito tenta retornar ao mundo estabilizado pela atribuição de sentidos, pelo estabelecimento de relações.

Nesse ínterim, pergunta a autora, como fica o trabalho do autor? Segundo ela, toda escolha implica exclusões, e isso não se dá de forma consciente. O sujeito ocupa a posição de autor quando procura amarrar a dispersão que sempre se instala virtualmente devido à equivocidade da língua. Assim, efetuase um processo de retorno ao enunciado, permitindo olhá-lo de outro lugar: o lugar de autor.

O autor está, portanto, constantemente renunciando e descartando outras formas de dizer. É por isso que podemos dizer que a escrita é marcada pela falta, pela perda, pois é preciso cercar a dispersão para haver um efeito de fecho. Pensando que as palavras não recobrem totalmente o mundo e admitindo a existência do real da língua, Tfouni traz o exemplo de um pequeno texto de Gilberto Gil:

"Mário Lago: o mar, o rio e o lago."

Esse gesto de interpretação produzido por Gilberto Gil para o nome de Mário Lago, segundo Tfouni, denuncia a deriva e instala a autoria. Marca o caráter resvalante da língua, que justamente caracteriza a deriva.

Em certos momentos, como ocorre em um texto científico, por exemplo, o autor tenta controlála usando as palavras de diferentes formas. No entanto, mesmo conseguindo conter a dispersão, não se consegue controlar o equívoco da língua e, portanto, a deriva sempre se instaura. Para o sujeito autor, no entanto, a deriva é ponto de apoio, seja para criar novas retóricas a fim de evitá-la, seja para escancará-la, como faz Gilberto Gil.

Finalmente, retomamos o que Tfouni ressalta desde o início de sua conferência: se os discursos produzidos oralmente também são considerados letrados, a autoria se instaura também aí, de uma outra forma. Nesses casos, ocorre a autoria em ato, uma réplica do processo de produção de textos escritos, que nos dá acesso, enquanto analistas, à perda das retificações e correções que o discurso escrito teria apagado. 


\title{
REVISTA DA ABRALIN
}

\author{
REFERÊNCIAS
}

GALLO, Solange Leda. Discurso da escrita e ensino. Campinas: Editora da Unicamp, 1992.115p.

LETRAMENTO e Autoria: dispersão e deriva de sentidos. Conferência apresentada por Leda Tfouni, 2020. 1 vídeo (1h 14min). Publicado pelo canal da Associação Brasileira de Linguística. Disponível em: <https://aovivo.abralin.org/?id=BVjUjK1Ep4k>. Acesso em: 06 jun. 2020.

PÊCHEUX, Michel. O discurso: estrutura ou acontecimento. Trad. Eni Orlandi. Campinas: Pontes, 1990. 